\title{
Making abstract mathematics concrete in and out of school
}

\author{
David Swanson • Julian Williams
}

Published online: 6 February 2014

(C) The Author(s) 2014. This article is published with open access at Springerlink.com

\begin{abstract}
We adopt a neo-Vygotskian view that a fully concrete scientific concept can only emerge from engaging in practice with systems of theoretical concepts, such as when mathematics is used to make sense of outside school or vocational practices. From this perspective, the literature on mathematics outside school tends to dichotomise in- and outof-school practice and glamorises the latter as more authentic and situated than academic mathematics. We then examine case study ethnographies of mathematics in which this picture seemed to break down in moments of mathematical problem solving and modelling in practice: (1) when amateur or professional players decided to investigate the mathematics of darts scoring to develop their "outing" strategies and (2) when a prevocational mathematics course task challenged would-be mathematics teachers' concept of fractions. These examples are used to develop the Vygotskian framework in relation to vocational and workplace mathematics. Finally, we propose that a unified view of mathematics, outside and inside school, on the basis of Vygotsky's approach to everyday and scientific thought, can usefully orientate further research in vocational mathematics education.
\end{abstract}

Keywords Vygotsky · Abstract and concrete mathematics · Vocational mathematics · In and out of school

\section{Introduction}

In this paper, we approach vocational mathematics education from a neo-Vygotskian perspective, centred on a particular view of what constitutes scientific conceptualisation and activity. The experimental and theoretical work of Vygotsky (1986) and his colleagues led to a distinction between scientific concepts, everyday concepts and various forms of preconceptual thought. He stressed, however, that this categorisation was a theoretical one and that, in practice, for adults, these forms can co-exist, that movement frequently occurs from one form to the other and that no clear dividing line exists between them. What differentiates conceptual thought (whether everyday or scientific) from the prior developmental forms, in

D. Swanson $(\bowtie) \cdot J$. Williams

School of Education, The University of Manchester, Manchester, UK

e-mail: david.swanson@postgrad.manchester.ac.uk

J. Williams

e-mail: julian.williams@manchester.ac.uk 
this framework, is argued to be a qualitative change in the relationship between abstract and concrete (1998, p. 37).

We take the term abstract in this context to refer to the unity of two processes: first, the act of grouping or synthesis and, second, the act of separating or analysis (the basis on which things are grouped). This second process also, at times, provides a narrower usage for the term abstraction in Vygotsky's work. Concrete, in its loosest sense, we take as the real world but, more specifically, the "perceptual" or "practical, action-bound thinking" based on sensory impressions or function, respectively (1986, p. 138). For Vygotsky, processes of abstraction play a role in development from an early stage, but in true conceptual thought, it is necessary to view "the abstracted elements apart from the totality of the concrete experience in which they are embedded" (p. 135). "A concept emerges only when the abstracted traits are synthesised anew and the resulting abstract synthesis becomes the main instrument of thought" (p. 139).

For Vygotsky, what then signifies scientific thought, in comparison to everyday conceptual thought, is that the concepts are also part of an organised system. The type of system is important here, as everyday concepts can also be part of systems (see Davydov, 1990), for example: brother, sister, mother, and so on, provides an early "everyday" system of relationships. Our view is that, just as in pre-conceptual thought, where meaning remains tied to the perceptual and practical, everyday concepts tend towards systematisation based on relationships in perception and practical activity. The systems of scientific thought, although ultimately rooted in such relationships, are formed instead on the basis of logical and scientificincluding mathematical-relationships.

Therefore, everyday concepts, despite in one sense uniting abstract and concrete, are still dominated by the surface relations or connections perceived in everyday practice. Scientific concepts, in contrast, encourage and require "conscious and deliberate control" through being "placed within a system of relations of generality" (Vygotsky, 1986, p. 172). Vygotsky's stress is on the role of schooling in introducing such forms of thought, although he was equally aware of the danger of "empty verbalism" if such systems are learnt (or memorised) without rich development in relation to the concrete (p. 150). He paid less attention to the use of scientific concepts outside of school but the implication is that the same bi-directional process between abstract systems and living reality can occur. However, in order for this to happen, we would suggest stressing the second half of the dictum by Marx (1992): "It is not enough for thought to strive for realization, reality must itself strive towards thought" (p. 252). That is to say, for a scientific system to become concrete (or vice versa), a need or problem must arise in practice which cannot easily be satisfied or overcome by less conscious, everyday means.

From this perspective, then, we will now consider workplace mathematics (as well as its relation to everyday mathematics, vocational schooling and schooling more generally).

\section{Mathematics outside school and in the workplace: selected literature}

Our current understandings of workplace mathematics are rooted in the challenge by Lave (1988) and others to the dominant cognitivist separation of cognition from activity: "What you learn is bound up with what you have to do" (Scribner 1985, p. 203). The form that mathematical activity takes was rightly argued to be highly situation dependent and distributed across mind, body, activity, other people, artefacts, setting and so on. The richer meaning and complexity of activity outside of school therefore meant there was a need to reverse the relative marginalisation, or outright dismissal, of the mathematical activity of everyday life. The arithmetic that, for example, supermarket shoppers (Lave, Murtaugh, \& de la Rocha, 1984), or street sellers (Carraher, Carraher, \& Schliemann, 1985), engaged in was not only qualitatively different but 
was also found to be more accurate and foolproof than when the same subjects engaged in apparently isomorphic school mathematics. In the outside world, people were more "in control of their activities, interacting with the setting, generating problems in relation with the setting and controlling problem solving processes" (Lave, 1988, p. 70), using other resources more, and arithmetic less, but in a more integrated and meaningful way.

Studies of mathematics in the workplace were integral to this wider category of everyday or street mathematics and were the source of many findings. For example, Nunes, Schliemann, and Carraher (1993) found "both flexibility and transfer were more clearly demonstrated for everyday practices than for the school-taught proportions algorithm" (p. 126), when investigating proportional knowledge in the workplace. Such practices could utilise and preserve meaning due to their derivation from activity which has a purpose, allowing social and empirical rules to be utilised alongside logical relationships, thus increasing the complexity that could be dealt with and decreasing the errors. Similar findings have been noted in a variety of vocations, for example, within nursing (Noss, Pozzi, \& Hoyles, 1999), where a practical meaning of the notion of an average is seen to be more efficient and effective than the school mathematics versions due to it being "webbed" together with practical and professional expertise.

Re-conceptualising all this in Vygotskian terms and within Activity Theory generally (see Blunden, 2010), we suggest that these activities have their motives in production, and mathematics becomes embedded in such activities just to the extent that it is functional to the activity. This fossilization (Vygotsky, 1997, p. 71) of the mathematics - often in physical artefacts, or in procedures, or fused in situated concepts - means that the acting subject is generally barely aware of the mathematics embedded there. It is concrete but not theoretical for them. This does not preclude the existence of abstraction or elements of abstract systems within the process which can aid limited forms of generalisation to contexts with similar elements, as in Nunes et al. (1993), or in the situated abstractions of Noss, Hoyles, and Pozzi (2002). But the dominant system remains the perceptual and action-bound one in which they are embedded, thus limiting conscious awareness and control of the mathematical system per se.

In contrast to everyday and workplace mathematical activity, the situated cognition literature above has variously characterised school mathematics as inauthentic, procedural, calculation driven, detached from meaning, passive, formal, formulaic, algorithmic, learned by rote and lacking specific purpose. In terms of the framework we have outlined, this could be the "empty verbalism" described earlier. However, we would argue that it illustrates not just the weak interrelation with the concrete in school mathematics, but also weak attention to the systemic nature of the abstract formal system too, as school curricula often atomize topics and limit the systemic connections that can be made in mathematics (e.g., Gainsburg, 2012).

These criticisms of schooling have encouraged efforts to bring the concrete reality of the workplace or outside into schools as curriculum tools so as to encourage more meaningful and purposeful activity there (Wake \& Williams, 2000; Williams \& Wake, 2007a), although with the understanding that transition between contexts is problematic (Nicol, 2002; Straesser, 2000). Such approaches are then also seen as better preparation for the reality of the workplace (e.g., Bakker, Kent, Derry, Noss, \& Hoyles, 2008). In addition, vocational education can design approaches and tools which more efficiently develop situated knowledge within the workplace (e.g., Bakker, Groenveld, Wijers, Akkerman, \& Gravemeijer, 2012).

However, alongside this, it has been suggested that changes in the demands of the modern workplace require a rethinking of the relationship with school, at least for a minority. The black-boxing of mathematics in artefacts (Latour, 1987) and in activity systems (see, e.g., Williams \& Wake, 2007a) is seen to be problematic as the nature of demands on employees changes. "Making the invisible visible," by opening up these black boxes, could then help improve efficiency, production and profitability (Bakker, Hoyles, Kent, \& Noss, 2006). It is 
argued, for example, that a key skill deficit among mid-level employees is not so much in performing calculations, but in understanding systems, particularly when development or communication with others is required: There is at times a need to "understand, at some level, the model behind a given symbolic artifact" (Hoyles, Noss, Kent, \& Bakker, 2010, p. 173). This, for us, seems to provide illustration of the type of scientific activity described by Vygotsky: such an approach advocates that mathematical systems and knowledge need to be consciously brought to bear on the job in workplace practice - which then heralds a scientific, theoretical understanding of workplace practice.

Boundary crossing and third space contexts (e.g., Tuomi-Gröhn \& Engestrom, 2003; Williams \& Wake, 2007a; Hahn, 2011; Akkerman \& Bakker, 2011) can thus also be used to bring academic/theoretical practices and practical/vocational work practices together, integrating the two types of knowledge, assisted by the awareness which can arise due to the contrasting approaches (Bakker \& Akkerman, 2013).

The purpose of this paper is to show how our neo-Vygotskian perspective provides a unified understanding of mathematics in work, school and vocational mathematics education. In relation to the overview of the literature above, this perspective leads us to suggest: (a) that the potential for scientific thought/activity can arise more widely than situated cognition perspectives, or even the recent vocational literature, allow for; (b) that these possibilities may be frustrated in practice by the structures of the workplace (and that these restrictions are similar to the ones encountered in schooling); and (c) that, nevertheless, both school and work are potential sites for scientific thought and practice, particularly, if the similar limiting structures in both are consciously challenged.

We illustrate these points, and the wider unifying perspective that Vygotsky's theory of scientific concepts provides, by exploring some unusual cases of work/outside-school mathematics and vocational schooling from this perspective.

\section{Methodology}

We choose to look at case studies of mathematics education that may be revealing because they are close to the boundary between school and work, either just outside in leisure/work (darts players) or just inside (schooling of would-be mathematics teachers). These cases are special, in that they provide vantage points from which to question and problematise vocational and school mathematics. We also briefly revisit a third vocational case, as a useful corrective, in order to establish doubt about the benign or authentic, situated nature of workplace activity in a traditional setting with a hierarchical division of labour (further details of this case are to be found in Williams \& Wake, 2007a, b).

The motivation for the two main cases was their occurrence far from equilibrium, in sites where interesting things may happen and where contradictions are more likely to be exposed. Darts players provide an interesting case of situated mathematics involving people with generally modest academic attainment, dealing with a complexity of mathematics beyond simple everyday arithmetic, where systemic mathematical thinking may become advantageous. Similarly, a case of a connectionist (Askew, Brown, Rhodes, William, \& Johnson, 1997) mathematics classroom was investigated, where the aim of learners becoming teachers themselves added an additional interrelating layer to the students' perceptions and discussions of concrete - but imagined - vocational practices.

Both studies adopted an ethnography-light approach (i.e., in adopting ethnographic practices but without full immersion or long-term engagement). Darts players were observed during practice and tournaments and interviewed both in relation to incidents which occurred during 
observation and regarding their wider practice. Autobiographies of professional darts players, and online discussion forums for players, also provided useful material and context. Similarly, the adult student, would-be teachers were recorded during their classes and interviewed along with their tutor, both in relation to observations and otherwise. All other relevant materials, including artefacts, were also collected or recorded where possible.

Our general approach to knowledge is to take a totality perspective (see Lukacs, 1967). We believe that integrating analyses across diverse case studies can, at times, allow us to go beyond the inherent limitations of more partial viewpoints and can also help subject generalised theory to the appropriate stress of demanding cases.

\section{Calculating at the oche: darts in leisure and work}

Darts is a game where players stand at the oche (a line marked $2.369 \mathrm{~m}$ from the face of the dartboard, measured horizontally) and throw small sharp sticks called darts at a board which has been carefully segmented into sections worth different points (see Fig. 1). Historically, this game became popular in working class clubs and pubs, but recently, with world television deals, the game has become seriously competitive and professional.

The different radial sections of the dart board target score 1 to 20 points, doubles and triples of those numbers in the outer ring and inner ring respectively, and 25 and 50 for the central rings known as the bulls eye. The most common form of the game involves each player starting at a score of 501 and taking it in turns to throw three darts until one player reduces their score to exactly zero - but crucially ending on a dart that counts double; that is, going out with a double.

The game in fact offers excellent opportunities for practice with numbers in a fun context. However, the most interesting mathematics of the game occurs for players beyond a certain minimal skill level as the end of the game approaches. Here, the aim shifts from simply throwing at the section which that gives the highest points - typically, treble 20 - to a more complex strategy which that weighs up the most useful section to throw at that makes finishing easiest. For example, when a player gets down to a score of 67 , they could go out by scoring treble 19 then double 5, say. But if they start with three darts, it would be better to go for treble 17 then double 8, because a narrow miss on treble 17 may score a single 17, and they would still have a double (the bulls eye counts as a double) to aim at. Or if, instead, they get treble 17

Fig. 1 Dartboard layout: the outer ring scores double, inner ring treble and bulls eye 25 and 50

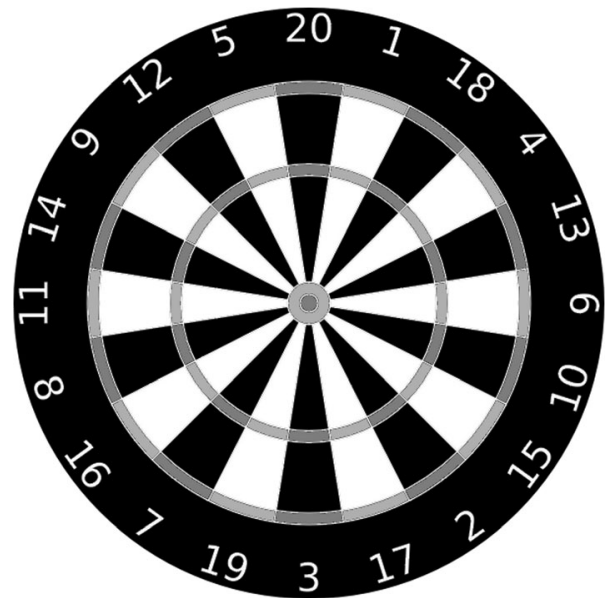


but miss the double 8 , hitting a single 8 , that would still leave double 4 to go out with. On such slim differences, a game and a match might be decided. The factors are multiple, but include (a) the probability of hitting the section aimed at, (b) what is likely to be hit if the dart misses (such as a single when aiming for a double or treble) and (c) whether the chosen path leads to a good double to end on-that is, one practised often (commonly, 20, 16 or 8) but, more importantly, a number than can be divided by two repeatedly, since, for example, missing double 16 is likely to score single 16 leaving double 8 , and so on.

In our investigations, we found the mathematics of this part of the game to be classically situated for players: the development of know-how in any situation takes place over a long period of time as skill increases, is highly concrete and context dependent, integrated with artefacts and involves apprenticeship in the society of those with more advanced knowledge. In fact, most darts players reported little or no memory of learning their numerical strategies with "you just pick it up" being a common account. Furthermore, much of this know-how has been crystallised in the outs table that players can download from the internet and carry in their pockets (see Fig. 2).

However, despite the classically situated and embedded nature of the mathematics for most people, there are two key ways in which something beyond this develops. The first comes through engagement and interest in the game, and, through that, the mathematical aspects. This could perhaps be termed intrinsic motivation, although, given its interrelation with practice in the real world, this term never quite feels adequate. We will rather call it the scientific motivation: the interest to get to the bottom of the theory of a situation of interest, which motivates genuinely theoretical, scientific intellectual development of a practical phenomenon. It is also often associated with prior mathematical confidence, as one top professional illustrates in his autobiography:

At school I was always good at maths; my maths got me into Hackney Downs Grammar School when I took the 11 plus exam. Darts was an extension of this. I'd spend hours working out different permutations to finish on, all that sort of thing.

\section{DARTS OUT CHART} Wwanson Q.

\begin{tabular}{|c|c|c|c|}
\hline 170 & T2O T20 DB & 142 & T20 \\
\hline 169 & NO 3 DART OUT & 141 & T20 T19 D12 \\
\hline 168 & NO 3 DART OUT & 140 & T20 T16 D16 \\
\hline 167 & T20 T19 DB & 139 & T20 T13 D20 \\
\hline 166 & NO 3 DART OUT & 138 & T20 T18 D12 \\
\hline 165 & NO 3 DART OUT & 137 & T20 T15 D16 \\
\hline 164 & T20 T18 DB & 136 & T20 T20 D8 \\
\hline 163 & NO 3 DART OUT & 135 & T20 T17 D12 \\
\hline 162 & NO 3 DART OUT & 134 & T20 T14 D16 \\
\hline 161 & T20 T17 DB & 133 & T20 T19 D8 \\
\hline 160 & T2O T20 D20 & 132 & T20 D20 D16 \\
\hline $15=$ & NO 3 DART OUT & 131 & T20 T13 D16 \\
\hline 158 & T20 T20 D19 & 130 & T20 T18 D8 \\
\hline 157 & T20 T19 D2O & 129 & T19 D2O D16 \\
\hline 156 & T20 T20 D18 & 128 & T20 D18 D16 \\
\hline 155 & T20 T19 D19 & 127 & T19 D19 D16 \\
\hline 154 & T20 T18 D20 & 126 & T20 D17 D16 \\
\hline 153 & T20 T19 D18 & 125 & T19 D18 D16 \\
\hline 152 & T20 T2O D16 & 124 & T18 T18 D8 \\
\hline 151 & T20 T17 D20 & 123 & T19 D17 D16 \\
\hline 150 & T20 T18 D18 & 122 & T20 D15 D16 \\
\hline 149 & T20 T19 D16 & 121 & T19 T16 D8 \\
\hline 148 & T18 T18 D20 & 120 & T20 520 D20 \\
\hline 147 & T20 T17 D18 & 119 & T19 D15 D16 \\
\hline 146 & T20 T18 D16 & 118 & T20 S18 D20 \\
\hline 145 & T20 T15 D20 & 117 & T20 S17 D20 \\
\hline 144 & T20 T20 D12 & 116 & T20 520 D18 \\
\hline & T20 T17 D16 & 115 & T19 S18 D20 \\
\hline
\end{tabular}

\begin{tabular}{|c|c|}
\hline 114 & $\mathrm{~T} 20 \mathrm{~S} 14$ \\
\hline 113 & T19 S16 D20 \\
\hline 112 & T20 520 D16 \\
\hline 111 & T19 S14 D20 \\
\hline 110 & T20 S18 D16 \\
\hline 109 & $\mathrm{~T} 20 \mathrm{~S} 17 \mathrm{D} 16$ \\
\hline 108 & T20 516 D16 \\
\hline 107 & T20 S15 D16 \\
\hline 106 & T20 S14 D16 \\
\hline 105 & T19 S16 D16 \\
\hline 104 & T20 S12 D16 \\
\hline 103 & T20 S11 D16 \\
\hline 102 & T20 S10 D16 \\
\hline 101 & T19 S12 D16 \\
\hline 100 & T20 D20 \\
\hline 99 & T19 S10 D16 \\
\hline 98 & T20 D19 \\
\hline 97 & T19 D20 \\
\hline 96 & T20 D18 \\
\hline 95 & T20 S3 D16 \\
\hline 94 & T18 D20 \\
\hline 93 & T19 S4 D16 \\
\hline 92 & T20 D16 \\
\hline 91 & T17 D20 \\
\hline 90 & T18 D18 \\
\hline 89 & T19 D16 \\
\hline 88 & T16 D20 \\
\hline 87 & T17 D18 \\
\hline
\end{tabular}

86 T18 D16 85 T15 D20 84 T2O D12 $83 \mathrm{~T} 17 \mathrm{D} 16$ 82 T14 D2O 81 T19 D12 80 T16 D16 79 T13 D2O $78 \mathrm{~T} 18 \mathrm{D} 12$ 77 T15 D16 76 T2O D8 $75 \quad \mathrm{~T} 17 \mathrm{D} 12$ 74 T14 D16 73 T19 D8 72 D20 D16 71 T13 D16 $70 \mathrm{~T} 18 \mathrm{DB}$ 69 T15 D12 68 D18 D16 67 T17 D8 66 D17 D16 65 T11 D16 64 T16 D8 63 T13 D12 $62 \quad 015$ D16 61 T15 D8

Fig. 2 A typical outs chart showing one way to go out with three darts 
They let me leave [school] 6 months early, well before my sixteenth birthday. There was no point in staying: I wouldn't have passed my exams because I didn't do any work. I was just mad at school, nuts. I told the teachers I didn't need an education because I was going to play darts, so that's why they signed me off for the last 6 months and told me I could go home. (Bristow, 2010, p. 22)

The second, and more likely, path for situated mathematics to develop is in the emergence of a need that cannot be satisfied in the old way. This is often focused around a breakdown moment, whereby actions that have become automatic fail in some way and thus become the subject of conscious attention (for a description rooted in Leontiev's work, see Williams \& Wake, 2007a; and a similar approach in Pozzi, Noss, \& Hoyles, 1998). For example, one of the non-professional players we interviewed reported:

It were a bit scary, when I started playing in the leagues. I were only 18, and I realised once, in a match, nobody's allowed to tell you which way you can go. You can only ask what's left. So I remember once hitting a strange treble and I looked and I knew I wanted... I can't remember the number, maybe it was 67 left, and I just didn't know which way to go for that... and everybody is looking at me, and I just didn't know... and I just went, "Wow, I don't know what to do now, I've got two darts left in me hand and I'll have to go for something!".

I were keen, I just didn't want the embarrassment of not knowing what to throw for, so I taught myself. I went to a lot of bother to find out simplest way to finish under 150. I had to ask which way would you go for that and why, and then eventually I'd work my own ways out. I thought, "No I'm better off doing that, because that leaves me treble 20 and bull or treble 18 and bull".

Bobby George, a professional player, relates a similar tale in his autobiography:

"There's no way you can lose playing like that", Roy [his friend and fellow player] said. What he didn't know, of course, was that I still couldn't count to save my life. I was faced with a 90 out-shot to beat Roger and win the title but I didn't have a clue how to go about it. "Treble 18, Bob", he shouted from the floor. Well, I hit treble 18 but my mind was still a complete blank about what I should do next. Nerves sometimes make moments like that even worse and I just stood at the oche bewildered, looking for help. .. It is no wonder some of the older players despaired of me. I admit it was a bloody ridiculous state of affairs.

Deep down I knew I had to rely on myself to progress. Another Essex player, Glen Lazero, and I worked out each and every possible permutation... My game improved almost overnight. I saw how trebles and singles that sit next to each other on the board can work in your favour... I was never any good at mathematics at school but I found that darts is more about remembering numbers and combinations. I had to crack this and it took some time... To this day, I don't do any form of arithmetic when I play darts. I just know how all the numbers work...Working out all those combinations gave me confidence. (George, 2007, p. 55)

As can be seen in both cases, deliberate attempts to memorise can play a role in such processes, and, from the outside, the end result may be indistinguishable from that of being simply memorised (see Vygotsky, 1978, p. 64). But, again in both cases, breakdown moments have led to a move beyond the situated, to an active working out involving systematic mathematical work. In this conscious process, systemic relationships (of the number system, 
the layout of the board and rules of the game) are united with the individual's history, concrete experience and everyday conceptualisations. For example, George explains:

I have always liked 121 as an out-shot for the simple reason that there are so many ways to hit it. Just think about it. Numbers 14 and 11 are next to each other so immediately there is one large treble target to hit. After that, there are lots of options - treble 14 leaves you treble 19 and double 11. Treble 11 leaves you treble 20 and double 14. Single 11 leaves you treble 20, bull, and single 14 leaves you treble 19, bull. You can never have too many options in darts. (George, 2007, p. 57)

Whereas the growth of mathematical expertise of the player in the early/middle stages appears gradual and incidental, picked up as they go, when the player gets seriously competitive (whether as a competitive club player or a professional, it makes little difference), there comes the moment when the strategy needs to be perfected, and the mathematics must be personally and individually tailored and mastered to achieve a high level of competence.

Even at this point, a player is likely to go to the default darts outs table for an answer (see Fig. 2). But growth of expertise requires that this table be generalised (to include all potential combinations) and specialised (to the tastes and skills of the player, e.g., some prefer to aim at the bull rather than certain trebles, etc.). It is at this moment that the mathematical work of the darts player approaches that of an investigation of the type likely to be conducted in scientific mathematics in academe or school. We hypothesise that these moments, while perhaps rare in practice, can arise in almost all leisure and workplace activities. We argue that this involves a genuinely scientific conceptualisation in practice in Vygotsky's sense. Notice, though, that after the mathematical work has been done, the know-how may again become automated in the darts player's own memory as their personal outs repertoire.

The experience of mathematics used by the darts players here offers a case where leisure meets professional work: the mathematics arose from a perceived need to develop the darts expertise required to perform at the top level, whether as a club player or a professional and champion. The motive for the activity is therefore almost identical in both cases, but actually raises potential differences between mathematics outside school and in work, due to this being such a special occupation. The professional darts player is a rare profession in that it emerges from a leisure activity, and the player goes professional in the game at a high level of special expertise. In other words, they are rather unlike those workers who have to sell their labour in a mass market of employees. We suspect that the majority see their work as a means to an end rather than as a vocation (in the sense of a calling) and are far less likely to be motivated to engage in such processes of working out problems mathematically. Even when they are so motivated, the division of labour is likely, directly or indirectly, frustrate them (for some evidence of workplace disengagement, see Gallup, 2013). Thus, while we celebrate this case, we are aware that all too often, in workers' experiences, mathematics may rarely present itself as the answer to a question. We therefore now revisit a study of just such a workplace example.

\section{Mathematics in a hierarchical workplace}

One of the main findings of Williams and Wake (2007a) was that workplace systems historically structure and hide the mathematics in two ways: first, as is well known, work 
processes tend to hide mathematics in artefacts and tools; second, the division of the labour process in the workplace tends to produce knowledge boundaries inside the workplace institution. These two processes work together to reduce the mathematical demands of the labourer in general and to privilege the activity of some few workers whose status may be related to their position of power/knowledge and also their competence (including mathematical competences).

Williams and Wake (2007a) provided details of one professional engineer in a large power plant, whom we called "Dan," whose status as the expert in charge of the spreadsheet formulae was maintained by a division of labour in which those operatives below him were cut off from access to the meaning of these formulae: their own work was reduced to reading dials and filling in record sheets that supplied Dan with the data needed to predict the plant's consumption of power. On the other hand, there are also boundaries around management who also are sometimes cut off, or black-boxed, from the knowledge of what is going on lower down in the industrial hierarchy. Such a division of labour appears to work - as long as there are no obvious breakdowns. But when breakdowns occur, suddenly the need to cross boundaries requires the black boxes to be opened and the automated mathematics to be re-vivified, which is quite often non-trivial (Williams \& Wake, 2007b; see also Noss et al., 2002).

However, the power relations and competition within the workplace that allow for a specialist to acquire special authority may not be functional at the broader, system level, as they tend to encourage a lack of transparency and a lack of openness. In general, unequal power relations imply a lack of equal sharing of knowledge in a common enterprise that would normally be expected in a community of practice (Wenger, 1998). Upon examination Dan's spreadsheets and recording instruments seemed to the outsider researchers to be unhelpfully opaque. In general, Williams and Wake (2007a, b) found that tools in the workplace are often idiosyncratically designed, as there seems to be less motivation to produce clarity of expression than one might expect (cf. non-experts reading a computer manual).

Finally, we can reflect that workplaces are not so very different from schools regarding mathematics. Based on cases such as Dan's, the operator classes are given routine and unchallenging mechanical tasks to do, while only those who are more privileged are likely to be given work that is challenging and highly valued (see Braverman, 1998). Indeed, we can add to this evidence even from ethnographies of industrial scientific practices: case studies by Latour and many others have shown how power and politics are engaged in the construction of science and scientific knowledge due to competitive divisions of labour (Latour \& Woolgar, 1986).

From our reading of the literature, we conclude that workplaces are often far from benign as places of authentic learning and that vocational mathematics is often structured by the power relations associated with a classed division of labour in ways that may be alienating for some workers, or would-be workers. The exigencies of practice in the workplace can cut workers off from thinking and communicating mathematically, and therefore from developing the sort of scientific conceptualisations that Vygotskian theory describes. However, there is the parallel point that school is also sometimes - perhaps as often - just as alienating for the majority of students, but for opposite reasons. The theoretical concepts of mathematics are, at least potentially, present, but aspiring workers may not become engaged in a productive, motivating practice, other than passing — or failing to pass - regulatory tests.

We will now consider a case in which some scientific mathematical work arose, apparently authentically, in schooling. Our intention here is to complicate this story of the alienation of workers and students from mathematics. 


\section{Would-be teachers troubled by fractions}

As discussed earlier, academic and school mathematics are rightly viewed as being formal. However, we would also agree that there is a didactic transposition between mathematics as a professional practice to mathematics for the classroom (Chevallard, 1988). What results is school - and institutionally - situated (Ozmanter \& Monaghan, 2008), and often involves a situated formalism involving transmissionist teaching and learning, with the memorisation and repetition of atomised process skills. Such pedagogy is contested, for example, by connectionist approaches (Askew et al., 1997), which stress, among other aspects, the connections within mathematics, connections to the real world (and students' own knowledge) and the use of dialogue in meaningful problem solving. Here, we explore a case where such an approach seemed to support a move from the situated formalism of most schooling to something more scientific. We do this by looking at a particular case of prevocational mathematical schooling provided for potential teachers of mathematics.

That the mathematics required for mathematics teaching is a form of (pre-) vocational mathematics may seem incongruent to some, but the arguments for seeing school mathematics as situated must be assumed to apply just as much to its teaching. This is to some extent recognised within the teacher education literature, where mathematical knowledge for teaching is seen as "a kind of professional knowledge of mathematics different from that demanded by other mathematically intensive occupations, such as engineering, physics, accounting or carpentry" (Ball, Hill, \& Bass, 2005, p. 17). What is different is often the paramount need for clarity of communication, and this requires an understanding of the audience or learner. This leads, for instance, to the need for multiple explanations and the ability to see or anticipate difficulties, misconceptions and errors. Arguably, these are, or should be, as important to the programmer of a computer operating system, an engineer trying to explain the potential dangers of extremely cold weather to the Challenger's O-rings (which led to the NASA space shuttle disaster in 1986) or in the case of Dan's spreadsheet formula. Yet, in industry, there is an ever-present bottom line of functioning that does not always prioritise transparency, clarity and even functionality.

\subsection{Mathematics Enhancement Courses}

Mathematics Enhancement Courses (MEC) are aimed at adults in the UK who wish to progress onto a secondary mathematics, pre-service Initial Teacher Training pathway, but who have been judged to have insufficient or insufficiently recent mathematical qualifications. The courses vary in length and pattern of attendance, depending on the previous mathematical experience of the students (in the case below this was 5 days per week for 36 weeks). The students primarily learn mathematics, but the courses can also include some classes on wider aspects of education and forms of teaching practice activities, with some limited contact with schools. Courses are funded by the UK Training and Development Agency for Schools, and thus there are no fees and a relatively reasonable weekly bursary which attracts students from a wide range of previous backgrounds.

The government specification for MEC stresses "connectedness as against fragmentation" and "deep and broad understanding of concepts, as against surface procedural knowledge" (Stevenson, 2008, p.103). Beyond this, there are fewer curriculum and assessment constraints for individual institutions than when they provide more traditional prevocational mathematical qualifications. This may allow a space for teachers to teach in a less regulated way and, through this, to provide alternative instructional practices. It is also relevant that the tutor in this case was an experienced mathematics teacher, educator and researcher whose beliefs are 
consistent with connectionism. We now turn to a study of one instructional sequence in relation to the wider issues of this article.

\subsection{A case of fractions: troubling the theoretical concept in practice}

The students, in this and a previous class, had been exploring the early Egyptian method of dealing with fractions, primarily through investigative and discursive problem solving activity. The issue of addition of fractions arose in this context and, in particular, the fraction addition $1 / 2+$ $1 / 3=5 / 6$. A student raised a common error, suggesting that $1 / 2+1 / 3=2 / 5$. This mistake is thought to arise from an overemphasis on procedure at the expense of theoretical understanding and may be related to treating the form of fraction multiplication as analogous to addition. Numerator is added to numerator and denominator added to denominator. The MEC tutor saw an opportunity in this discussion and raised the possibility of a pupil having, instead, based their answer on their experience with test results. If, say, they had been given "one out of two" for the first question in a test, and "one out of three" for a second question, how much would they have scored altogether? Two out of five (or two fifths or $40 \%$ ) would be regarded as the correct answer in this context.

This led to some audible confusion among the students as they realised that this was true, yet went against their normal understanding of how fractions work. The tutor then invited them to discuss the problem in their different groups. The setting up of a contradiction within the students' conceptualisation (or the drawing to attention of a misconception) is a deliberate strategy, commonly used by the tutor as an aid to concept development.

Already in this situation, we can see some interesting combinations. We have both school and vocation - the students are learning mathematics but are doing so in a context of becoming teachers themselves at some point. Often, within the MEC class we studied, this second factor is implicit as the students go about their mathematical activity, but when it surfaces and becomes explicit, as it does in the dialogue that follows, it does so naturally, and there is never a sense that the class is now engaged in a different type of activity.

Our example contains both school mathematics and vocational mathematics. We have the formal rules of addition of fractions, yet the class is also addressing the way test scores are represented as fractions in class. Furthermore, this example engages with a classic element of mathematics for teaching, the understanding of misconceptions and how teachers might potentially respond. Finally, we also have formal, situated mathematics, alongside, at least potentially, a deeper conceptual understanding of the mathematics involved in test-scoring practices. Following Roth (2012), we could ask the question: Where are the boundaries between these aspects if they are all present in the classroom, potentially at any point? However, we (perhaps contra-Roth) would resist the idea that the subjective individual is the key unit of analysis for the unifying of the various factors in such cases. Many aspects of the activity bring these elements together, including, here, the instructional example itself. Although it is more obvious in this MEC case, we would argue that this is true, to an extent, in more general school/vocational cases (e.g., through the mathematics contained within classroom tools; see Williams \& Goos, 2013).

Returning to the problem before the class, the contradiction - that a half plus a third equals five sixths, yet, one out of two and one out of three, combined in a test, scores two out of five - is recognisably a question of modelling, but also, conceptually, of unitisation, a topic which has been well explored (see, e.g., Lamon, 1996). However, as the concept of unitisation could easily remain at a formal level, our own preferred understanding is one that relates both to the real world and a meta-understanding of what mathematical theory is. One version of this would be as follows: mathematics is a modelling practice which abstracts from the patterns and regularities of real, practical experience in the world. The fractions (and, more generally, 
numbers) that we use arose from this process historically, and therefore originally represent fractions and numbers of something (we note here the related and valid points made by Schmittau, (2003), on the relation of fractions to measurement rather than counting). As a culture, we have reified this process to produce numbers as objects in themselves and happily add 2 to 3 to get 5 , or teach that $1 / 2+1 / 3=5 / 6$, without reference to any mediating context other than the symbolic manipulation itself. What then becomes implicit and hidden is that in most real practices, such numbers have to be tied to a unit of something, and, in particular, when adding, the added numbers or values, and the total, need to refer to the same unit element (even in group or ring theory), and so of the same thing. So $1 / 2$ of something added to $1 / 3$ of the same thing equals $5 / 6$ of the same thing (even if that same thing is just the number " 1 "). In the contested example above, we could write $1 / 2$ of 2 marks $+1 / 3$ of 3 marks $=2 / 5$ of 5 marks which is also, in this context, true.

In the MEC class, we recorded a group of students on one table, where an initial discussion of the problem was followed by the following dialogue:

7 Beth [Attempted explanation:] Because that [one out of two] isn't half. Because that's not a real half. It's only half of your two possible marks, isn't it?

8 Dora It is a half though

9 Beth ...But it's not a half of the whole test though, is it.

10 Elise Yeah. The five questions are divided into two questions.

11 Beth There are five questions

12 Dora But this is like one over five isn't it and this is one over five. [writing $1 / 2=1 / 5$ and $1 / 3=1 / 5$ ]

13 Elise Oh that's just confusing. A half is equals a half. What? A half is equal to one fifth, isn't a half equal to a half?

We find this dialogue fascinating for many reasons. Beth, at line 7, already seems to have a concrete form of the conceptualisation we suggested above, although it includes a dismissal of "one out of two" as not being a "real" half. This reflects the formalism that students can bring with them when they first enter a path toward teaching. The generalised concept of unitisation is not explicitly expressed here, and Dora can counter the explanation with the obvious, "it is a half though". Yet Dora too, in line 12, can express a concrete form of the solution. Elise then asks a pertinent question - one that begs to be mathematised with multiple units.

This generalisation doesn't materialise in dialogue here, though, and the discussion is inconclusive; there is a pause and then a slight reformulation of the initial disagreement occurs:

\begin{tabular}{lll}
\hline 22 & Beth & Yeah, it's, sorry, it is two over five but it's not half \\
23 & Dora & But then they will say, "ok so..." \\
24 & Beth & Yeah it is two over five but it's not half plus a third is it. \\
25 & Dora & No... no but... \\
26 & Beth & 'Cause then you start looking at it going... \\
27 & Dora & I'm looking at it and thinking yeah.... \\
28 & Beth & It's right \\
29 & Dora & I agree [laughs] \\
& & [pause]
\end{tabular}

What is important for us here in this continuing to-and-fro between the formal and the contradictory concrete example is the line, "But then they will say". The "they" here refers to 
the idealised future students, the ones initially referenced by the tutor, who here mediate the MEC students' own expressions of doubt, and of needing to be convinced of their own argument. Potential student teachers of mathematics often come with an experience of transmissionist classrooms and a model of the teacher as expert, one who primarily must explain to others, and therefore one whose efficacy depends precisely on being convincing, if only to themselves (and it is perhaps in this sense that teachers will often say "I never really understood this concept until I had to prepare myself to teach it"). Here, we suggest, this imagined future demand sustains the dialogue beyond the point where the participants might otherwise have been motivated. The dialogue continues with Dora's reference to the test papers: They will see, in which each page of the test has a box for the marks scored on that page written as a fraction, the kids will see these boxes and know that they add the fractions up in just this way to get their total score:

30 Dora It's just that if you tell them to add them together. Of that one I get one and that one ....and you know how those test papers are, do you remember? There's a box, usually, that does say that. So it's like if you tell them to look at those as fractions. I never thought of that.

31 Beth Who would look at that?

32 Dora Kids will...

33 Beth Will they? Really?

34 Anna But you do. You'll get your result as a fraction, your teacher will write it as a fraction.

The conversation continues, retracing the previous argument about the fractional parts being different units:

\footnotetext{
41 Anna See what I mean it's not proportional.

42 Beth [very quickly] Yeah that's not half the marks for the whole test, that's half out of those two questions.

43 Dora Yeah, and that would be the difference

44 Beth But it's actually quite a hard concept to explain why it doesn't work, but you see easy why it's two fifths [pause]
}

The students here seem almost to have produced a satisfactory argument, that is, in a form that almost convinces them, but there remains an awareness that the concept is still not in an explicit form that resolves the contradiction adequately. The idea is still considered hard, and so perhaps too hard for them. There is a sense here of an ambiguity of meaning in the words they or them: the students as both learners (finding this argument hard to put together) and as imagined teachers (whose learners will expect them to be able to explain simply and clearly). This puts new heightened demands on their own learning, as they are learning, ultimately, to teach, which implies the argument must be better than almost persuasive.

An essentially transmissionist view of teaching, one based on the centrality of explaining, has here mediated students' awareness of a vocational form of mathematics required for teaching. At the same time, despite this transmissionist outlook, this orientation has affected their own learning, motivating them towards gaining a perhaps deeper understanding of the mathematical concepts involved.

What do we mean here by a deep understanding? We argue that this is precisely the dialectical synthesis of the systemic, theoretical mathematics of fractions with the concrete practice of teaching or explicit explaining as required for teaching. We argue that the discourse above shows these students as struggling to achieve this. The fact that this synthesis is perhaps not fully or adequately achieved is clear in their finishing in some doubt. The articulation of 
our own understanding preceding the above analysis was our attempt to articulate a sort of deep understanding that teaching practice might require.

The school work of these would-be teachers is special for two major, and distinct, reasons. First, it is characterised as schooling as the activity is clearly structured by the object of gaining a qualification from the MEC to enter teacher training. En route, the students' main task is to learn/acquire sufficient mathematics knowledge and skills to begin teaching. On entry to a teacher-training course, they will still be students, but their activity becomes hybrid, as they will enter classrooms and practice teaching (even while not yet being fully qualified and employed). Thus, these would-be teachers are as close to becoming workers/professionals as one can get while still being firmly students, that is, without actually practising their work/profession. What we find significant about this activity is that the students are already in role as imaginary, would-be teachers - that is, they envision themselves as teachers of the subject even while they are learning it. This role can be sufficiently strong to provide a motive for their learning activity, and it deserves to be called a vocational motive, even though they are not yet practising their vocation. We have seen this in other school contexts, where mathematics became embedded in the vocational work of engineering students (Black, HernandezMartinez, Davis, \& Wake, 2010). But the act of imagination is equally valid when a leisure, or other, activity is made real in the classroom - such as that of shopping, where the so-called situated intuition of purchasing and giving change can become useful in learning subtraction (see Williams, Linchevski, \& Kutscher, 2008).

\section{Conclusion}

Our aim has been to show how Vygotskian perspectives can help us to see how genuine scientific activity can arise, whether in school, work, or vocational mathematics education. In each of these cases, we have also suggested how such activity can be frustrated by institutional structures and how such structures might alienate learners and workers from scientific activity and thought. Mathematics can be ritualised and even fossilised in practices in both vocational and academic contexts. It was suggested that this arises from the embedding and automisation of mathematics in artefacts and operational procedures in production (and schooling) systems and that these evolve historically in systems with divisions of labour that black-box mathematics socially, as well as materially.

But we have also seen in case studies how this fossilisation of mathematics in practice can break down too and lead to activity of a mathematically scientific nature in Vygotsky's sense. In our perspective, mathematical authenticity is visible when the abstract "rises to the concrete" (Marx, 1973, p. 101). That is, formal theoretical-mathematical concepts are made concrete in practice by learners or workers solving concrete tasks, in meaningful social practices - whether in school or in workplaces.

A caveat: we allow that the activity of the university academic, for example, in ring theory is a practice and that proving new theorems is one socially meaningful, concrete product of mathematics. In the same way, we can have no problem with school children or construction workers being engaged in problem solving of a genuinely mathematical nature, as well as mathematics that enhances their scientific understandings of practices in the rest of life. We emphasise that it is the rules of the institutions (whether work or school) that may prevent workers and students from engaging in such activity. Why so?

In both cases, it seems the object of the institutional activity may conflict with genuinely useful and functional scientific learning with mathematics. In workplaces, the worker may be told, "It is not your job to think (about the O-rings), we have managers who will decide 
(whether the space shuttle Challenger flies);" while, in school, students may be told "Never mind why (minus times minus is plus), this is how to get the answer and pass your exams."

As researchers, we conveniently chose a workplace case study of the darts player, where the knowledge seemed less alienating as the work was close to fun. But we also conveniently chose an academic environment in which students were professionally motivated by understanding mathematics for teaching. Perhaps these are the exceptions, where, even in school, understanding and having to explain the mathematics becomes a priority, and getting the mathematics straight is crucial to being a top darts player. But we conveniently chose to make the point: that the dialectical opposition and synthesis of the systemic abstract with the concrete is what makes the difference in making mathematics scientific, whether it occurs in school or in work/leisure. In both cases, those involved were motivated to do so.

In conclusion, we would suggest that there are valuable forms of thought that, although never unsituated, do go beyond the situated to become scientific, in Vygotsky's sense of a conscious, mutually mediating systemic synthesis of the abstract and concrete. This is not to reverse the gains of situated cognition and devalue the most-of-the-time everyday practice of "just plain folks" (Lave, 1988), which we still hold as essential sources of scientific inquiry. It does, however, involve critiquing the institutionalised, situated formalism of most mathematics schooling, where test-taking rituals have sometimes substituted for scientific goals. A similar institutional critique can, in many cases, be extended to the workplace. Both schools and workplaces are contested arenas. If, at the moment, schools are far from ideal in developing scientific conceptual learning, workplaces are also often far from being ideal places where it can be expressed, or even developed. We believe it would aid the vocational mathematics literature to relate these two understandings more directly.

Acknowledgments David Swanson would like to acknowledge that this work was supported in part by the Economic and Social Research Council [grant number ES/J500094/1].

Open Access This article is distributed under the terms of the Creative Commons Attribution License which permits any use, distribution, and reproduction in any medium, provided the original author(s) and the source are credited.

\section{References}

Akkerman, S. F., \& Bakker, A. (2011). Boundary crossing and boundary objects. Review of Educational Research, 81(2), 132-169.

Askew, M., Brown, M., Rhodes, V., William, D., \& Johnson, D. (1997). Effective teachers of numeracy: Report of a study carried out for the Teacher Training Agency. London: King's College, University of London.

Bakker, A., \& Akkerman, S. F. (2013). A boundary-crossing approach to support students' integration of statistical and work-related knowledge. Educational Studies in Mathematics. doi:10.1007/s10649-013-9517-z.

Bakker, A., Groenveld, D. J. G., Wijers, M., Akkerman, S. F., \& Gravemeijer, K. P. E. (2012). Proportional reasoning in the laboratory: An intervention study in vocational education. Educational Studies in Mathematics. doi:10.1007/s10649-012-9393-y.

Bakker, A., Hoyles, C., Kent, P., \& Noss, R. (2006). Improving work processes by making the invisible visible. Journal of Education and Work, 19, 343-361.

Bakker, A., Kent, P., Derry, J., Noss, R., \& Hoyles, C. (2008). Statistical inference at work: The case of statistical process control. Statistics Education Research Journal, 7(2), 130-145.

Ball, D. L., Hill, H. H., \& Bass, H. (2005). Knowing mathematics for teaching: Who knows mathematics well enough to teach third grade, and how can we decide? American Educator, 29(1), $14-46$. 
Black, L., Williams, J., Hernandez-Martinez, P., Davis, P., \& Wake, G. (2010). Developing a 'leading identity’: The relationship between students' mathematical identities and their career and higher education aspirations. Educational Studies in Mathematics, 73(1), 55-72.

Blunden, A. (2010). An interdisciplinary theory of activity. Leiden, The Netherlands: Brill.

Braverman, H. (1998). Labour and monopoly capital: The degradation of work in the twentieth century. New York: Monthly Review Press.

Bristow, E. (2010). The crafty cockney: The autobiography. London: Arrow Books.

Carraher, T. N., Carraher, D., \& Schliemann, A. D. (1985). Mathematics in the streets and in schools. British Journal of Developmental Psychology, 3, 21-29.

Chevallard, Y. (1988, August). On didactic transposition theory: Some introductory notes. Paper presented at the International Symposium on Research and Development in Mathematics, Bratislava, Czechoslovakia.

Davydov, V. V. (1990). Soviet studies in mathematics education: Vol. 2. Types of generalization in instruction: Logical and psychological problems in the structuring of school curricula. Reston, VA: National Council of Teachers of Mathematics.

Gainsburg, J. (2012). Why new mathematics teachers do or don't use practices emphasized in their credential program. Journal of Mathematics Teacher Education, 15(5), 359-379.

Gallup Inc. (2013). State of the American workplace: Employee engagement insights for US business leaders. Washington, DC: Gallup.

George, B. (2007). Bobby dazzler: My story. London: Orion.

Hahn, C. (2011). Linking academic knowledge and professional experience in using statistics: A design experiment for business school students. Educational Studies in Mathematics. doi:10.1007/s10649-011-9363-9.

Hoyles, C., Noss, R., Kent, P., \& Bakker, A. (2010). Improving mathematics at work: The need for technomathematical literacies. London: Routledge.

Lamon, S. J. (1996). Partitioning and unitizing. In L. Puig \& A. Gutierrez (Eds.), Proceedings of the $20^{\text {th }}$ conference of the international group for the psychology of mathematics education (Vol. 3, pp. 233-240). Valencia, Spain: PME.

Latour, B. (1987). Science in action: How to follow scientists and engineers through society. Milton Keynes: Open University Press.

Latour, B., \& Woolgar, S. (1986). Laboratory life: The construction of scientific facts. Princeton, NJ: Princeton University Press.

Lave, J. (1988). Cognition in practice: Mind, mathematics and culture in everyday life. Cambridge, MA: Cambridge University Press.

Lave, J., Murtaugh, M., \& de la Rocha, O. (1984). The dialectic of arithmetic in grocery shopping. In B. Rogoff \& J. Lave (Eds.), Everyday cognition: Its development in social context (pp. 95-116). Cambridge, MA: Harvard University Press.

Lukacs, G. (1967). History and class consciousness. London: Merlin.

Marx, K. (1973). Grundrisse: Foundations of the critique of political economy. Harmondsworth: Penguin

Marx, K. (1992). A contribution to the critique of Hegel's philosophy of right. Introduction (1843-4). In Early writings (pp. 243-259). London: Penguin.

Nicol, C. (2002). Where's the math? Prospective teachers visit the workplace. Educational Studies in Mathematics, 50(3), 289-309.

Noss, R., Hoyles, C., \& Pozzi, S. (2002). Abstraction in expertise: A study of nurses' conceptions of concentration. Journal for Research in Mathematics Education, 33(3), 204-229.

Noss, R., Pozzi, S., \& Hoyles, C. (1999). Touching epistemologies: Meanings of average and variation in nursing practice. Educational Studies in Mathematics, 40, 25-51.

Nunes, T., Schliemann, A. D., \& Carraher, D. W. (1993). Street mathematics and school mathematics. Cambridge, MA: Cambridge University Press.

Ozmanter, M. F., \& Monaghan, J. (2008). Are mathematical abstractions situated? In A. Watson \& P. Winbourne (Eds.), New directions for situated cognition in mathematics education (pp. 103-127). New York: Springer.

Pozzi, S., Noss, R., \& Hoyles, C. (1998). Tools in practice, mathematics in use. Educational Studies in Mathematics, 36, 105-122.

Roth, W.-M. (2012). Rules of bending, bending the rules: The geometry of conduit bending in college and workplace. Educational Studies in Mathematics. doi:10.1007/s10649-011-9376-4.

Schmittau, J. (2003). Cultural-historical theory and mathematics education. In A. Kozulin, B. Gindis, V. S. Ageyev, \& S. M. Miller (Eds.), Kygotskyś educational theory in cultural context (pp. 225-245). Cambridge: Cambridge University Press.

Scribner, S. (1985). Knowledge at work. Anthropology and Education Quarterly, 16, 199-205.

Stevenson, M. (2008). Profound understanding of fundamental mathematics: A study into aspects of the development of a curriculum for content and pedagogical subject knowledge. Proceedings of the British Society for Research into Learning Mathematics, 28(2), 103-108. 
Straesser, R. (2000). Mathematical means and models from vocational contexts - a German perspective. In A. Bessot \& J. Ridgway (Eds.), Education for mathematics in the workplace (pp. 65-80). Dordrecht, The Netherlands: Kluwer.

Tuomi-Gröhn, T., \& Engeström, Y. (2003). Between school and work: New perspectives on transfer and boundary-crossing. Oxford: Pergamon.

Vygotsky, L. V. (1978). Mind in society. London: Harvard University Press.

Vygotsky, L. V. (1986). Thought and language. London: MIT.

Vygotsky, L. V. (1997). The collected works of L. S. Kygotsky. Vol. 4: The history of the development of the higher mental functions. New York: Plenum.

Vygotsky, L. V. (1998). The collected works of L. S. Vygotsky. Vol. 5: Child psychology. New York: Plenum.

Wake, G. D., \& Williams, J. S. (2000, August). Can workplace practice inform design of mathematics curricula? Paper presented to the International Congress of Mathematics Education, Tokyo, Japan.

Wenger, E. (1998). Communities of practice: Learning, meaning, and identity. Cambridge: Cambridge University Press.

Williams, J., \& Goos, M. (2013). Modelling with mathematics and technologies. In M. A. Clements, A. J. Bishop, C. Keitel, J. Kilpatrick, \& F. K. S. Leung (Eds.), Third International handbook of mathematics education (pp. 549-569). New York: Springer.

Williams, J. S., Linchevski, L., \& Kutscher, B. (2008). Situated intuition and activity theory fills the gap. In A. Watson \& P. Winbourne (Eds.), New directions for situated cognition in mathematics education (pp. 153178). New York: Springer.

Williams, J. S., \& Wake, G. D. (2007a). Black boxes in workplace mathematics. Educational Studies in Mathematics, 64(3), 317-343.

Williams, J. S., \& Wake, G. D. (2007b). Metaphors and models in translation between college and workplace mathematics. Educational Studies in Mathematics, 64(3), 345-371. 